\title{
Preferential Provision of Medicines - Economic Problems and the Need for Reforming
}

\author{
Okonenko T.I. \\ Yaroslav-the-Wise Novgorod State University, \\ Veliky Novgorod, Russia, \\ Tatyana.Okonenko@novsu.ru \\ Tokmachov M.S. \\ Yaroslav-the-Wise Novgorod State University, \\ Veliky Novgorod, Russia, \\ Mikhail.Tokmachov@novsu.ru
}

\author{
Antropova G.A. \\ Yaroslav-the-Wise Novgorod State University, \\ Veliky Novgorod, Russia, \\ Galina.Antropova@novsu.ru
}

\section{Egorova E.S.}

Yaroslav-the-Wise Novgorod State University, Veliky Novgorod, Russia,

Eugenia.Egorova@novsu.ru

\author{
Khrutsky A.K. \\ Medical Diagnostic Center, \\ Veliky Novgorod, Russia, \\ khrutsky@mail.ru
}

\begin{abstract}
The aging of the population in the Russian Federation and other countries has led to an increase in the number of chronic non-communicable diseases requiring higher costs of medical care. A $10 \%$ increase in the proportion of the aging population with chronic diseases reduces economic growth by $0.5 \%$ per year. Therapy with genetically engineered biological preparations for chronic diseases of the musculoskeletal system is burdensome for regional budgets, because patients suffering from these diseases receive drugs under the subsidized drug provision. The article discusses the need to reform the system of preferential provision on the example of RA patients receiving genetically engineered biological drugs (GEBD). Among all RA patients who chose preferential drug provision, the proportion of patients receiving GIBP grew from $1.88 \%$ in 2011 to $6.20 \%$ in 2017 with a further tendency to decline, which is probably due to the fact that in the period 2018-2019 in the Novgorod region, there was a change in the procedure for receiving GIBP by patients with RA. Since 2019, their purchase has been made only by the regional clinical hospital as part of the provision of hightech medical care, and patients with $R A$ receive them parenterally in the rheumatology department, where they are hospitalized for 1-2 days. Therefore, most likely, such a reorganization of the system is associated with a decrease in drug procurement in 2018. In addition, such a system for providing patients with preferential drugs is also designed to eliminate interruptions in the provision of "preferential" prescriptions with necessary drugs.
\end{abstract}

Keywords-regional budget, financing of pharmaceutical provision, price, preferential drug provision

\section{INTRODUCTION}

All citizens of the Russian Federation have the right to free drug provision as part of the provision of medical care to them on the basis of the current Program of state guarantees of free provision of medical care to citizens.

The aging of the population in the Russian Federation and other countries has led to an increase in the number of chronic non-communicable diseases requiring higher costs of medical care. Therefore, the growth in the level of health care costs outstrips the growth of the gross domestic product. An increase in the proportion of the aging population suffering from chronic diseases by $10 \%$ reduces economic growth by $0.5 \%$ per year, leading to a cumulative increase in economic damage [1].

Rheumatoid arthritis (RA) is a chronic disease that occurs more often between the ages of 30 and 60 years, accompanied by many comorbid conditions, and is the most common and costly of all rheumatic diseases [2]. The cost of an annual course of treatment for a patient with RA is on average 15637 euros [3].

Significant advances in the drug therapy of rheumatic diseases are associated with the introduction into practice of innovative drugs (MP), which include genetically engineered biological drugs (GEBD). The use of such a GEBD as Infliximab in the pharmacotherapy of RA makes it possible to achieve remission in $50 \%$ of patients. The cost of an annual treatment with Infliximab for one RA patient is about 
1.5 million rubles. In Russia, according to various sources, from $2.79 \%$ to $10 \%$ of patients with RA receive GEBD [4].

GEBD therapy refers to high-tech methods of treatment, therefore it is selected and prescribed to patients in a hospital. But RA is a chronic disease, therefore, the patient should also receive drugs on an outpatient basis at the place of residence. For GEBD users, the cost of RA treatment has increased and accounts for more than half of all direct medical expenses [5, $6]$. At the same time, direct costs of treatment increased from 4914 to 8206 euros for patients aged 18-64 years and from 4100 to 6221 euros for patients over the age of 65 [7].

The high cost of GEBD limits their use [8].

The territorial program of state guarantees free provision of medical care to citizens is being implemented from the funds of the constituent entity of the Russian Federation, which is developed annually on the basis of the Decree of the Government of the Russian Federation No 890 of July 30, 1994 "On state support for the development of the medical industry and improving the provision of the population and healthcare institutions with medicines and medical products" (as amended on February 14, 2002). The patient receives drugs for the treatment of RA itself for free, drugs for the treatment of comorbid conditions are paid for from their own pocket. It should be noted that guaranteed drug supply to the population is carried out in conditions of budget deficit at all levels $[9,10]$. Therefore, to manage socio-economic processes in difficult economic conditions, it is important to analyze the timing series of various economic indicators.

\section{PRoBlem STATEMENT}

The purpose of the article is to study the provision of patients with RA with genetically engineered biological drugs within the framework of preferential drug provision on the territory of a constituent entity of the Russian Federation and to substantiate the need to reform the system of preferential provision on the example of patients with RA who receive these drugs.

To solve the set goals, the following tasks are formulated:

1) study the incidence of RA in Russia and the Novgorod region during 2010-2018;

2) analyze the range of genetically engineered drugs prescribed to patients with RA and receiving free MP in the system of preferential drug provision;

3) estimate the proportion of prescribed prescriptions for genetically engineered biological drugs out of all submitted prescriptions by patients who have chosen the system of preferential drug provision.

\section{RESEARCH METHODS}

The functioning of the drug supply system for citizens of the Russian Federation is determined by "restrictive" lists of drugs [11]. Therefore, the objects of the study were Federal Law No 323-FZ "On the Fundamentals of Health Protection of Citizens in the Russian Federation" dated November 21, 2011; Decree of the Government of the Russian Federation No 932 "On the program of state guarantees of free provision of medical care to citizens for 2014 and for the planning period 2015 and 2016" dated October 18, 2013; Federal Law No 230-
FZ "On Amendments to Certain Legislative Acts of the Russian Federation in Connection with Improving the Delineation of Powers" dated October 18, 2007; Decree of the Government of the Novgorod Region dated December 20, 2013 No 472 "On the territorial program of state guarantees of free provision of medical care to citizens for 2014 and for the planning period of 2015 and 2016" (as amended by decrees of the Government of the Novgorod region of March 19, 2014 No 169, of July 15, 2014 No 375); List of vital drugs (vital essential and essential drugs) for 2014 (Order of the Government of the Russian Federation No 2199-r dated December 7, 2011 of the year); List of VED for medical use for 2015 (Order of the Government of the Russian Federation dated December 30, 2014 No 2782-r), Order of the Ministry of Health of Russia dated December 24, 2012 No 1470 n "On approval of the standard of primary health care for rheumatoid arthritis", statistical compilations on the incidence of the population of Russia in 2010, 2012, 2014, 2016 and 2018, a database of RA patients of the state regional budgetary healthcare institution "Medical Information and Analytical Center" who receive genetically engineered drugs under the territorial and federal programs of preferential drug provision. The personal data of patients who were on preferential drug provision were encrypted.

To process the obtained data arrays, content analysis, a graphical method, and mathematical methods (study of timing series; statistical analysis; construction and study of regression models; forecasting along a trend) were used.

\section{FINDINGS}

Analysis of incidence rates in the period 2010-2018 showed that the incidence of RA in the Novgorod region is almost twice as high as in the Russian Federation, and tends to increase (according to the forecast), the peak incidence was noted in 2014 with a value of 567.8 (Fig. 1).

Content analysis of medical prescriptions of the GEBD for 2010-2018 determined the following nomenclature of drugs: INN (international non-proprietary name) Abatacept, INN Infliximab, INN Rituximab, INN Tocilizumab, INN Ustekinumab, INN Certolizumab pegol, INN Etanercept. It should be noted that the medical arsenal within the framework of preferential provision has expanded significantly in the period of 2010-2011. Thus, in 2010, prescriptions include Infliximab only (the average number of prescribed prescriptions for a drug per patient is 3.308) and Rituximab (the average number of prescribed prescriptions is 3.205). In 2011, in addition to the forenamed drugs, Abatacept, Tocilizumab and Etaneracept appeared. In addition to qualitative changes in the structure of appointments of this period, there are quantitative changes. The average number of prescribed prescriptions for the drug per patient increased and amounted to 5.25 for Abatacept, 4.0 for Tocilizumab, 6.5 for Etaneracept; 5.0 for Infliximab. This indicator remained without significant changes only for Rituximab - 3.0.

In the period of 2012-2015, prescriptions were supplemented with one more item, Certolizumab pegol began to be prescribed. The average number of prescribed prescriptions remains high, but varies from year to year depending on the GEBD. The analysis did not reveal any trend in the fluctuations of this indicator. For example, for Abatacept this figure was 7, 167 - in 2012, 8.625 - in 2013, 
$8.750-2014,2.375-2015,5.700$ - in 2016. For Infliximab, the data ranged from $4.42012,5.167$ - in 2013, up to $5.647-$ in 2014 the maximum value was reached -7.067 in 2015 ; in 2016, there was a decrease in the number of prescribed prescriptions to 6.9. The average number of prescriptions for Rituximab per patient decreased from 4.333 in 2012 to 2.3 in 2013 and then varied slightly from 2.8 in 2014 to 2.486 in 2015 .

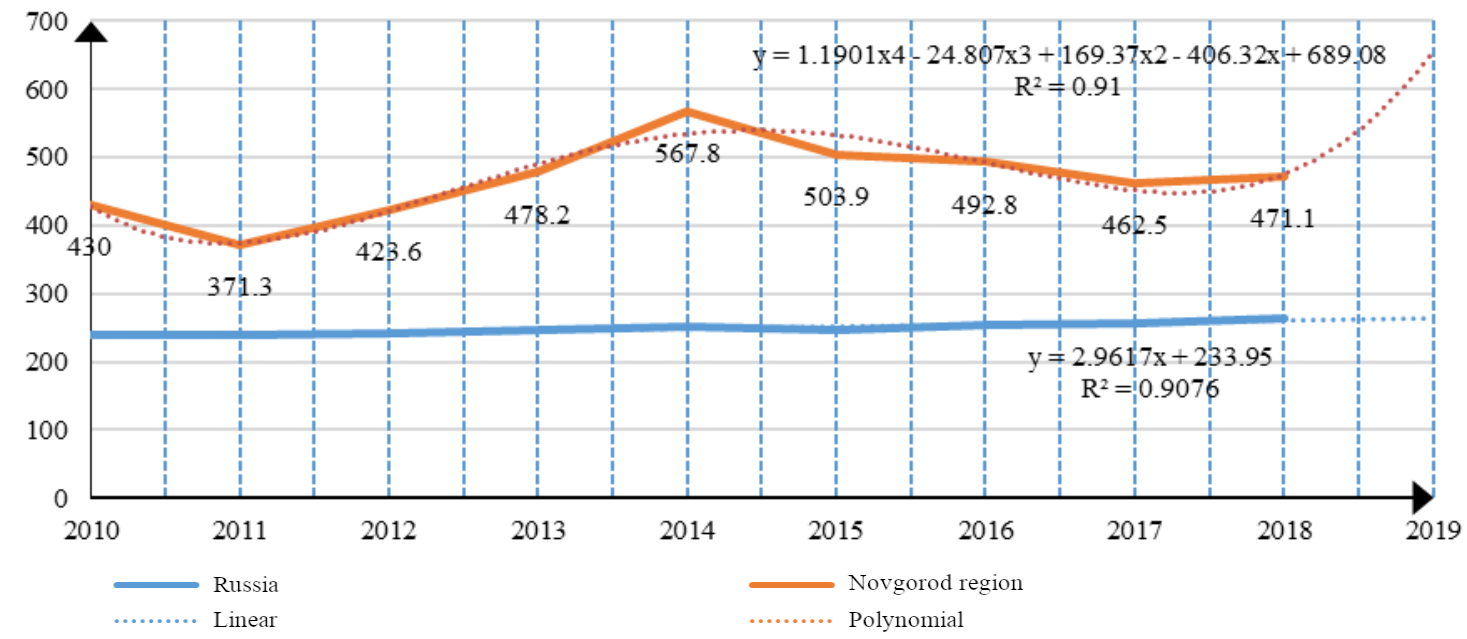

Fig. 1. The incidence of rheumatoid arthritis in Russia and the Novgorod region per 100.000 population

The number of prescribed prescriptions to one patient for Tocilizumab was one of the highest 13.0 in 2012, 12.0 in $2013,7.125$ in $2014,6.5$ in $2015,8.778$ in 2016.A consistently high value of this indicator is observed for Etanercept: $8.75-$ in $2012,9.0$ - in $2013,7.091-2014,8.615$ - 2015, 8.417 - in 2016.

In 2016, in addition to the listed medicinal products (MP), Ustekinumab was being prescribed. The average number of prescribed prescriptions per patient was rather small and amounted to 2.0. The largest assortment of GEBD was noted in 2017 with an average prescription rate per patient of 1.923 for Abatacept, 6.625 for Infliximab, 1.828 for Rituximab, 8.250 for Tocilizumab, 4,000 for Ustekinumab, 6.000 for Certolizumab pegol and 9.100 for Etanercept. In 2018 there was a noticeable reduction in the average number of prescribed prescriptions for Infliximab (1.667), Rituximab (1.0), Tocilizumab (5.2), Entarnecept (8.0). Prescriptions for Abatacept, Ustekinumab, Certolizumab pegol were discontinued, although the frequency and spectrum of adverse drug reactions of Certolizumab pegol were generally consistent with those for other inhibitors of tumor necrosis factor.

The high cost of GEBD is a significant obstacle to effective therapy.

One of the options for reducing the cost of treatment is the purchase of similar biological medicinal products, often in this case, a decrease in costs is observed several times. Mainly the following similar biological medicinal products are purchased: Remicade and Flammegis (INN Infliximab), Acellbia (INN Rituximab), Dalibra (INN Adalimumab).

Among all RA patients who chose preferential drug provision, the proportion of patients receiving GEBD increased from $1.88 \%$ in 2011 to $6.20 \%$ in 2017 with a further downward trend (Fig. 2).

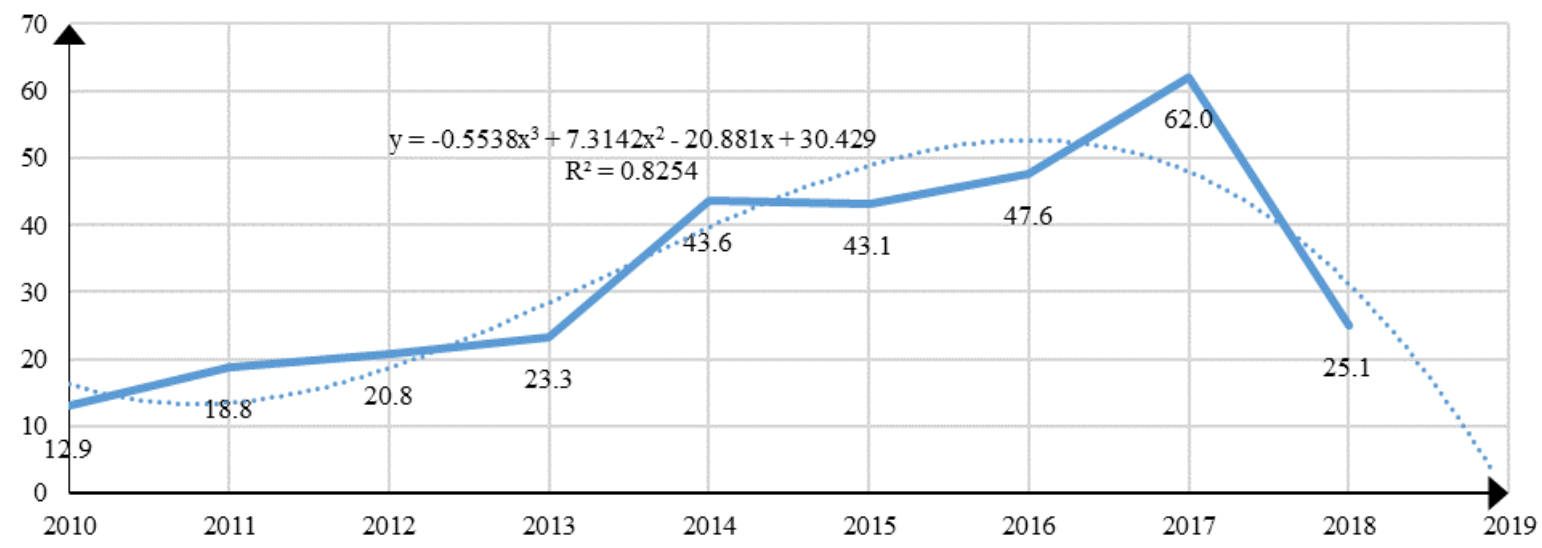

Fig. 2. The proportion of patients with rheumatoid arthritis who received genetically engineered biological drugs among all those who chose preferential drug provision (\%)

The same trends as for the proportion of RA patients receiving GEBD persisted when analyzing the number of prescribed prescriptions for GEBD, only the growth of the indicator has stopped since 2016. The failure in the 2015 schedule is apparently due to the instability of drug procurement (Fig. 3). 


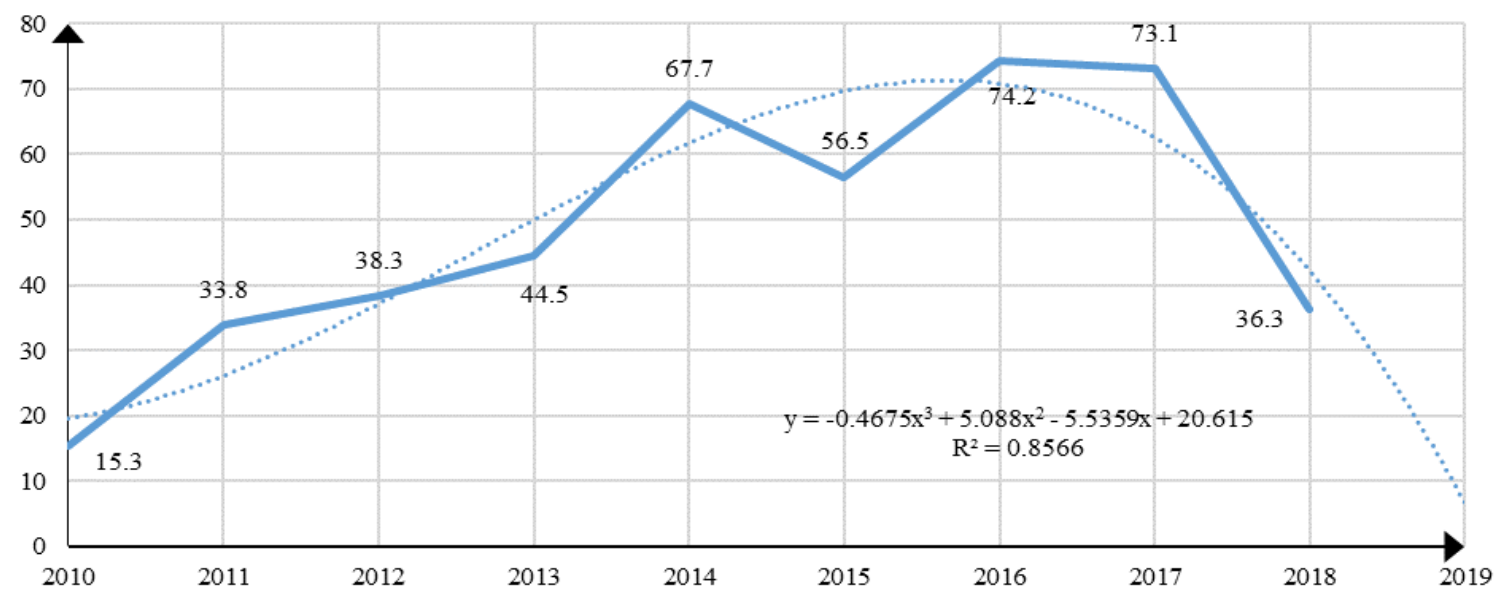

Fig. 3. Percentage of prescribed prescriptions for genetically engineered biological products out of all the prescriptions presented by RA patients (\%o)

According to the forecast, the number of patients will increase, while the number of beneficiaries will decrease significantly. The processes will go in opposite directions.

The main factors contributing to the outflow of patients from the drug benefit program are significant differences in their needs and preferences for drugs.

The high cost of GEBD is a significant obstacle to effective therapy. One of the options for reducing the cost of treatment is the purchase of similar biological medicinal products, often in this case, a decrease in costs is observed several times. Mainly the following similar biological medicinal products are purchased: Remicade and Flammegis (INN Infliximab), Acellbia (INN Rituximab), Dalibra (INN Adalimumab).

\section{CONCLUSION}

The share of beneficiaries who were assigned GEBD constantly grew during the study period and reached $6.2 \%$ in 2017, i.e. RA patients receiving expensive drugs remained in the drug benefit program. According to studies carried out in Russia, on average, the proportion of patients receiving GEBD was $2.79 \%$, the main share $-30-36 \%$ of prescriptions of GEBD were in three centers, in three more $-10-12 \%$, in the rest - up to 5\% [12]. Total annual health care costs for RA patients are gradually increasing, 3 times higher than the cost of treating patients without RA (\$ 20.919 vs. \$ 7.197), with the main cost factor being outpatient costs and direct costs, reaching $87 \%[13,14]$. The state program Medicare already in 2013 in terms of insurance coverage of the costs of prescription drugs, practically reached the limit and with difficulty provided RA patients receiving GEBD. In Washington DC patients with RA who need GEBD are included in co-insurance programs and bear up to $30 \%$ of the cost of biological drugs [15].

It becomes clear that in the conditions of the territorial budget deficit, such a financial burden is critical for it, which probably led to a decrease in the number of prescribed drugs. This entails untimely receipt of the drug, its replacement, and decreased patient compliance. Outpatient medical care is ineffective because free or low-cost medicines are often not provided in a timely manner.
Many states seek to create conditions for citizens to receive affordable medical care, including preferential drug provision.

In our country, a system of preferential drug provision has been created for certain categories of the population suffering from diseases that fall under certain nosological units included in the lists of various levels. This system requires reforming because: monetization is chosen by more than half of the citizens who have the right to be provided with the necessary medicines. Those patients remain in the system who need regular intake of expensive medicines (such as GEBD), which leads to a difference between the allocated funds and the actual financial resources spent on the purchase of medicines.

In the period 2018-2019 in the Novgorod region, a change was made in the procedure for obtaining GEBD by patients with RA. Since 2019, their purchase is carried out only by the regional clinical hospital as part of the provision of high-tech medical care and patients with RA receive them parenterally in the rheumatology department, where they are hospitalized for 1-2 days, receiving not only treatment, but also the necessary follow-up examinations and recommendations of a rheumatologist. Therefore, most likely, such a reorganization of the system is associated with a decrease in the procurement of drugs in 2018, and the state of drug supply of GEBD in subsequent years requires a detailed analysis. In addition, such a system for providing patients with preferential medicines is designed to eliminate interruptions in the provision of "preferential" prescriptions with necessary drugs.

It seems possible to consider the option of sharing the costs of purchasing drugs by the state and the patient.

\section{References}

[1] V.S. Malichenko, S.B. Malichenko, and A.M. Yavisya, "Features of the organization of outpatient drug supply for certain population groups in the Russian Federation", Medical and Social Expert Evaluation and Rehabilitation. Russian Journal, 2016, vol. 19(2), pp. 103-108. (In Russ.). DOI: https://doi.org/10.18821/1560-9537-2016-19-2-103-108

[2] A. Urman, N. Taklalsingh, C. Sorrento, and I.M. McFarlane, "Inflammation beyond the Joints: Rheumatoid Arthritis and Cardiovascular Disease", Scifed J Cardiol, 2018, vol. 2(3), 1000019.

[3] J.S. Smolen, D. Aletaha, and I.B. McInnes, "Rheumatoid arthritis", Lancet, 2016, vol. 388(10055), pp. 2023-2038

[4] I.Yu. Zinchuk, and V.N. Amirdzhanova, "Social burden of rheumatoid arthritis”, Rheumatology Science and Practice, 2014, vol. 52(3), pp. 331- 
335. (In Russ.). DOI: http://dx.doi.org/10.14412/1995-4484-2014-331335

[5] M. Benucci, V. Rogai, F. Atzeni, V. Hammen, P. Sarzti Puttini, and A. Migliore, "Costs associated with rheumatoid arthritis in Italy: past, present, and future", Clinicoecon Outcomes Res, 2016, vol. 8, pp. 33-41. DOI: https://doi.org/10.2147/CEOR.S91006

[6] A. Hresko, T.C. Lin, and D.H. Solomon, "Medical care costs associated with rheumatoid arthritis in the US: a systematic literature review and meta-analysis", Arthritis Care Res (Hoboken), 2018, vol. 70(10), pp. 1431-1438. DOI: https://doi.org/10.1002/acr.23512

[7] D. Huscher, T. Mittendorf, U. von Hinüber, I. Kötter, G. Hoese, A. Pfäfflin, S. Bischoff, and A. Zink, "Evolution of cost structures in rheumatoid arthritis over the past decade", Annals of the Rheumatic Diseases, 2015, vol. 74(4), pp. 738-745. DOI: https://doi.org/10.1136/annrheumdis-2013-204311

[8] S.B. Bekmurodzoda, Yo.U. Saidov, and Kh.R. Makhmudov, "Clinical and pharmacoeconomic aspects of active controlled anti-inflammatory therapy of rheumatoid arthritis, based on the principles of the «treat-totarget» strategy: current state of the issue", Avicenna Bulletin, 2019, vol. 21(1), pp. 141-146. (In Russ.). DOI: http://dx.doi.org/10.25005/2074-0581-2019-21-1-141-146

[9] L.L. Kvachaniya, "Economic peculiarities and problems of primary medicinal support”, Innov: electronic scientific journal, 2018, vol. 3(36). (In Russ.).

[10] A. Ovod, "Financing of pharmaceutical supply systems of the Russian
Federation", Innov: electronic scientific journal, 2017, vol. 4(33). (In Russ.).

[11] M.V. Sura, "Restrictive lists of drugs: regulations, functions, sources of finance, and guidelines for creation", Farmakoekonomika. Modern Pharmacoeconomic and Pharmacoepidemiology, 2017, vol. 10(1), pp. 46-56. (In Russ.). DOI: https://doi.org/10.17749/20704909.2017.10.1.046-056

[12] R.M. Balabanova, V.N. Amirdzhanova, and E.L. Nasonov, "Use of genetically engineered biological drugs for rheumatoid arthritis in the Russian Federation", Rheumatology Science and Practice, 2012, vol. 50(6), pp. 10-14. (In Russ.)

[13] P.-H. Hsieh, O. Wu, C. Geue, E. Mclntosh, I.B. Mclnnes, and S. Siebert, "Economic burden of rheumatoid arthritis: a systematic review of literature in biologic era", Annals of the Rheumatic Diseases, 2020, vol. 79(6), pp. 771-777. DOI: https://doi.org/10.1136/annrheumdis2019-216243

[14] C.-I. Chen, L. Wang, W. Wei, H. Yuce, and K. Phillips, "Burden of rheumatoid arthritis among US Medicare population: co-morbidities, health-care resource utilization and costs", Rheumatology Advances in Practice, 2018, vol. 2(1). DOI: https://doi.org/10.1093/rap/rky005

[15] J. Yazdany, R.A. Dudley, R. Chen, G.A. Lin, and C.W. Tseng, "Coverage for high-cost specialty drugs for rheumatoid arthritis in Medicare Part D”, Arthritis Rheumatol., 2015, vol. 67(6), pp. 1474 1480. DOI: https://doi.org/10.1002/art.39079 